\title{
Impact of mild exacerbation on COPD symptoms in a Japanese cohort
}

\author{
This article was published in the following Dove Press journal: \\ International Journal of COPD \\ 9 June 2016 \\ Number of times this article has been viewed
}

\author{
Minako Sato' \\ Shotaro Chubachi' \\ Mamoru Sasaki' \\ Mizuha Haraguchi' \\ Naofumi Kameyama' \\ Akihiro Tsutsumi' \\ Saeko Takahashi' \\ Hidetoshi Nakamura ${ }^{1,2}$ \\ Koichiro Asano 3 \\ Tomoko Betsuyaku' \\ 'Division of Pulmonary Medicine, \\ Department of Medicine, Keio \\ University School of Medicine, \\ Tokyo, ${ }^{2}$ Department of Respiratory \\ Medicine, Saitama Medical University, \\ Saitama, ${ }^{3}$ Division of Pulmonary \\ Medicine, Department of Medicine, \\ Tokai University School of Medicine, \\ Kanagawa, Japan
}

Background: Patients with COPD might not report mild exacerbation. The frequency, risk factors, and impact of mild exacerbation on COPD status are unknown.

Objectives: The present study was performed to compare features between mild exacerbation and moderate or severe exacerbation in Japanese patients with COPD.

Patients and methods: An observational COPD cohort was designed at Keio University and affiliated hospitals to prospectively investigate the management of COPD comorbidities. This study analyzes data only from patients with COPD who had completed annual examinations and questionnaires over a period of 2 years $(n=311)$.

Results: Among 59 patients with mild exacerbations during the first year, 32.2\% also experienced only mild exacerbations in the second year. Among 60 patients with moderate or severe exacerbations during the first year, $40 \%$ also had the same severity of exacerbation during the second year. Findings of the COPD assessment test and the symptom component of the St George's Respiratory Questionnaire at steady state were worse in patients with mild exacerbations than in those who were exacerbation free during the 2-year study period, although the severity of the ratio of predicted forced expiratory volume in 1 second did not differ between them. Severe airflow limitation (the ratio of predicted forced expiratory volume in 1 second $<50 \%$ ) and experience of mild exacerbations independently advanced the likelihood of an elevated COPD assessment test score to $\geq 2$ per year.

Conclusion: The severity of COPD exacerbation seemed to be temporally stable over 2 years, and even mild exacerbations adversely impacted the health-related quality of life of patients with COPD.

Keywords: COPD, chronic emphysema, COPD exacerbation, quality of life, comorbidity

\section{Introduction}

COPD is characterized by progressive and partially reversible airflow limitation, and it is among the leading causes of death worldwide. ${ }^{1}$ The disease is complicated by exacerbation, which is associated with a poor prognosis, ${ }^{2,3}$ and places a considerable economic burden on health services and society. ${ }^{4,5}$ It has also been recognized that some patients with COPD are particularly prone to exacerbations, and these patients have been termed "frequent exacerbators". ${ }^{6,7}$ Exacerbations are categorized into mild, moderate, and severe ones in terms of either clinical presentation (number of symptoms) or utilization of health care resources. ${ }^{8-10}$ Most of the published studies have surveyed moderate-to-severe exacerbation that required a change in regular medication or hospital admission. ${ }^{2,3,11}$ However, one observational study found that about half of all exacerbations remain unreported, yet the recovery periods are similar to those of moderate or severe exacerbations. ${ }^{12}$ Other studies have also shown that unreported exacerbations might negatively affect the health-related quality of life
Correspondence: Shotaro Chubachi Division of Pulmonary Medicine, Department of Medicine, Keio University School of Medicine, 35 Shinanomachi, Shinjuku-ku, Tokyo 160-8582, Japan

$\mathrm{Tel}+8 \mathrm{I} 353633406$

Fax +81333532502

Email bachibachi472000@live.jp
International Journal of COPD 2016: | | |269-1278

Dovepress ff in $\mathbf{0}$

http://dx.doi.org/10.21471COPD.S105454 (c) (1) (8) ( 2016 Sato et al. This work is published and licensed by Dove Medical Press Limited. The full terms of this license are avalable at https://www.dovepress.com/terms.php cc) hereby accept the Terms. Non-commercial uses of the work are permitted without any further permission from Dove Medical Press Limited, provided the work is properly attributed. For permission for commercial use of this work, please see paragraphs 4.2 and 5 of our Terms (https://www.dovepress.com/terms.php). 
(QOL) of patients ${ }^{13,14}$ and underline the importance of early detection of exacerbations and appropriate therapy.

The reported frequency of moderate or severe exacerbation is low among Japanese patients with COPD,${ }^{15-17}$ and lower than that in other countries. ${ }^{7}$ However, the frequency, risk factors, and impact of mild exacerbation on COPD status in a Japanese population of patients with COPD have not yet been clarified. We have been conducting a multicenter, observational cohort study to longitudinally examine the comorbidities of COPD in Japan, called the Keio COPD Comorbidity Research (K-CCR). We recently reported the findings of cross-sectional studies at enrollment showing associations between comorbidities and various aspects of COPD. ${ }^{18-20}$ Here, we aimed to compare the impact on the health-related QOL and pulmonary function between mild exacerbation and moderate or severe exacerbation in Japanese patients with COPD. The reported longitudinal changes in St George's Respiratory Questionnaire (SGRQ) categories and their determinants are markedly different between its categories. ${ }^{21}$ Therefore, we hypothesized that such differences would be more markedly seen when patients were classified based on the severity of exacerbation. We retrospectively reviewed the medical records of patients with COPD to detect the severity of all exacerbation events and applied a robust definition of exacerbation based on symptomatic and treatment criteria.

\section{Patients and methods Study populations}

An observational cohort study has been established at Keio University and affiliated hospitals to prospectively determine the optimal management of COPD comorbidities and register the findings with the University Hospital Medical Information Network (UMIN000003470). We enrolled 572 patients between April 2010 and December 2012, including those who had been diagnosed with COPD by pulmonary physicians and those referred for the assessment of possible COPD based on symptoms and/or presence of emphysematous changes on computed tomography (CT) images as described..$^{18,19}$ We analyzed only data from patients who had COPD confirmed by spirometry, had completed annual examinations and questionnaires, and had visited outpatient clinics at the participating hospitals monthly or bimonthly for regular clinical checkups for 2 years $(n=311)$. The ethics committees of Keio University and affiliated hospitals approved the study protocol, and each patient provided written informed consent to analyze and present their data. The study conforms in all respects to the Declaration of Helsinki adopted by the 59th WMA General Assembly, Seoul, Korea, October 2008.

\section{Assessment of exacerbation}

Doctors assessed whether COPD symptoms had worsened since the last assessment and required treatment during scheduled appointments or emergency presentation. Symptoms constituting an exacerbation were identified based on strict criteria adapted from the original definition of previous reports. ${ }^{10,22}$ Independent investigators in the present study retrospectively judged number and severity of exacerbations from reviews of physicians' medical records. Mild COPD exacerbation was defined as worsening of symptoms that were self-managed (by measures such as an increase in salbutamol use) and resolved without systemic corticosteroids or antibiotics. Moderate COPD exacerbation was defined as a requirement for treatment with systemic corticosteroids or antibiotics or both. Severe COPD exacerbation was defined as hospitalization, including an emergency admission for $>24$ hours.

\section{Assessment of clinical parameters and comorbidities}

All patients were clinically stable and without exacerbations for at least 1 month before study enrollment and the day of annual examinations. All questionnaires of health status, including all categories of SGRQ ${ }^{23-25}$ and the COPD assessment test (CAT), ${ }^{26,27}$ were completed at home while the disease was stable at baseline and then annually thereafter. All patients were also assessed by spirometry and CT imaging. The extent of emphysema was quantified as the ratio of low attenuation area $(\mathrm{LAA} \%)^{28}$ and the ratio of airway wall area (WA \% $)^{29}$ on CT images using custom-made software (AZE Ltd., Tokyo, Japan). ${ }^{19}$ Images of a Multipurpose Chest Phantom N1 (Kyoto Kagaku, Kyoto, Japan) were acquired at the start of the study to calibrate CT instrument from various manufacturers, which also enabled the assessment of longitudinal changes in LAA\% $\%{ }^{19}$ Comorbid diagnoses were established using clinical history and examination findings based on a review of available medical records as reported previously. ${ }^{18,19}$ Ophthalmological examinations were performed to estimate the prevalence of cataract.

\section{Statistical analysis}

Data are presented as mean \pm SD or as median \pm interquartile range. Data were compared between two groups using $t$-test, Mann-Whitney $U$-test, and $\chi^{2}$ test and among three groups using analysis of variance and the Tukey-Kramer, KruskalWallis, and $\chi^{2}$ tests. The effects of factors on minimal clinical important changes in CAT ( $\triangle \mathrm{CAT} \geq 2$ per year) were assessed using univariate and multivariate logistic regression 
analyses. ${ }^{30}$ Differences in levels of CAT, SGRQ, forced expiratory volume in 1 second $\left(\mathrm{FEV}_{1}\right), \mathrm{LAA} \%$, and in rates of change over time among three groups classified according to the severity of exacerbation were estimated using mixedeffects modeling ${ }^{31}$ with Bonferroni correction. Two-sided $P$-values of $<0.05$ were considered significant for all tests. Data were analyzed using the JMP 10 software (SAS Institute Inc., Cary, NC, USA). The mixed-effect model was applied using SPSS 23 (IBM Corporation, Armonk, NY, USA).

\section{Results}

\section{Frequency of various severities of exacerbations}

Table 1 shows the baseline characteristics of the study participants. The proportions of patients without exacerbation, with only mild exacerbations, and with moderate or severe exacerbations during the first and second years of follow-up were similar $(61.7 \%, 19.0 \%$, and $19.3 \%$ vs $68.2 \%, 14.5 \%$, and $17.4 \%$, respectively, $P=0.2029$ ). The frequency of moderate or severe exacerbation during follow-up (events per person per year) was 0.28. Only seven patients, comprising three patients in GOLD stage II, three patients in GOLD stage III, and one patient in GOLD stage IV, had more than two moderate or severe exacerbations per year.

\section{Temporal stability of exacerbation severity during follow-up}

Among 59 patients with mild exacerbations during the first year of follow-up, 19 (32.2\%) patients also experienced only mild exacerbations during the second year, and among 60 patients with moderate or severe exacerbations during the same period, $24(40.0 \%)$ patients also experienced

Table I Characteristics of study population

\begin{tabular}{ll}
\hline $\mathrm{n}$ & $3 \mathrm{II}$ \\
Female sex (\%) & $2 \mathrm{I}(6.8)$ \\
Age (years) & $72.6 \pm 8 . \mathrm{I}$ \\
Smoking index (pack-years) & $56.4 \pm 29.5$ \\
Current smokers (\%) & $38(12.5)$ \\
$\mathrm{BMI}\left(\mathrm{kg} / \mathrm{m}^{2}\right)$ & $22.7 \pm 3.1$ \\
$\mathrm{FEV} / \mathrm{IFVC}(\%)$ & $52.7 \pm \mathrm{II} .9$ \\
$\% \mathrm{FEV}$, & $62.9 \pm 20.7$ \\
COPD stages $^{\mathrm{a}} \mathrm{I} / \mathrm{II} / \mathrm{III} / \mathrm{IV}, \mathrm{n}(\%)$ & $69 / 152 / 72 / 18(22.2 / 48.9 / 23.2 / 5.8)$ \\
SGRQ total score & $23.8(13.7-38.4)$ \\
CAT score & $\mathrm{II}(6-17)$ \\
\hline
\end{tabular}

Notes: Data are shown as $n(\%)$, mean $\pm S D$, and median (interquartile range). a'Defined by Global Initiative for Chronic Obstructive Lung Disease.

Abbreviations: BMI, body mass index; CAT, COPD assessment test; $\mathrm{FEV}_{1}$, forced expiratory volume in I second; FVC, forced expiratory volume; $\% \mathrm{FEV}_{1}$, ratio of predicted FEV ; SGRQ, St George's Respiratory Questionnaire. the same severity of exacerbations during the second year (Figure 1).

\section{Comparison of baseline characteristics of patients grouped according to the severity of exacerbations}

We compared the characteristics among three groups of patients to determine the impact of exacerbation severity on COPD status during 2 years of follow-up. Patients were grouped according to whether they were exacerbation free $(\mathrm{n}=154)$, had only mild exacerbation (mild exacerbator, $\mathrm{n}=67$ ), or had at least one moderate or severe exacerbation (moderate/severe exacerbator; $n=90$ ). Table 2 shows the baseline characteristics of these groups. The ratio of predicted forced expiratory volume in 1 second $\left(\% \mathrm{FEV}_{1}\right)$ was significantly lower, and the LAA\% was higher in the moderate/ severe exacerbator compared with the mild exacerbator and exacerbation-free groups at baseline $\left(\% \mathrm{FEV}_{1}: 53.3\right.$ vs 65.4 and 67.4, $P=0.0006$ and $P<0.0001$, respectively; LAA\%: 20.3 vs 9.0 and $10.6, P=0.0013$ and $P=0.0004$, respectively).

\section{Comparison of comorbidities according to the severity of exacerbations}

Table 3 shows that the frequency of some comorbidities differed among the exacerbation-free, mild exacerbator, and moderate/severe exacerbator groups. The prevalence of gastroesophageal reflux disease (GERD) was higher in the mild exacerbator group than in the exacerbationfree group ( $46.2 \%$ vs $30.4 \%, P=0.0281)$. In contrast, the prevalence of anemia, cataracts, and prostatic hypertrophy was higher in the moderate/severe exacerbator group than in the exacerbation-free group (anemia: $29.7 \%$ vs $17.5 \%$, $P=0.0286$; cataract: $63.6 \%$ vs $40.4 \%, P=0.0044$; prostatic hypertrophy: $20.7 \%$ vs $8.7 \%, P=0.0100)$. The frequency of cardiovascular disease and depression did not significantly differ among the three groups.

\section{Relationship of exacerbations with FEV, and LAA\% during 2 years of follow-up}

The $\mathrm{FEV}_{1}$ was significantly lower in the moderate/severe exacerbator group than in the mild exacerbator and exacerbation-free groups during follow-up $(P=0.001$ and $P<0.001$, respectively) but did not differ between the mild exacerbator and exacerbation-free groups $(P=1.000$; Figure 2). The rate of change in $\mathrm{FEV}_{1}$ did not differ among the three groups during follow-up $(P=0.5446)$.

We analyzed only data from patients who underwent annual CT assessment more than twice and provided 


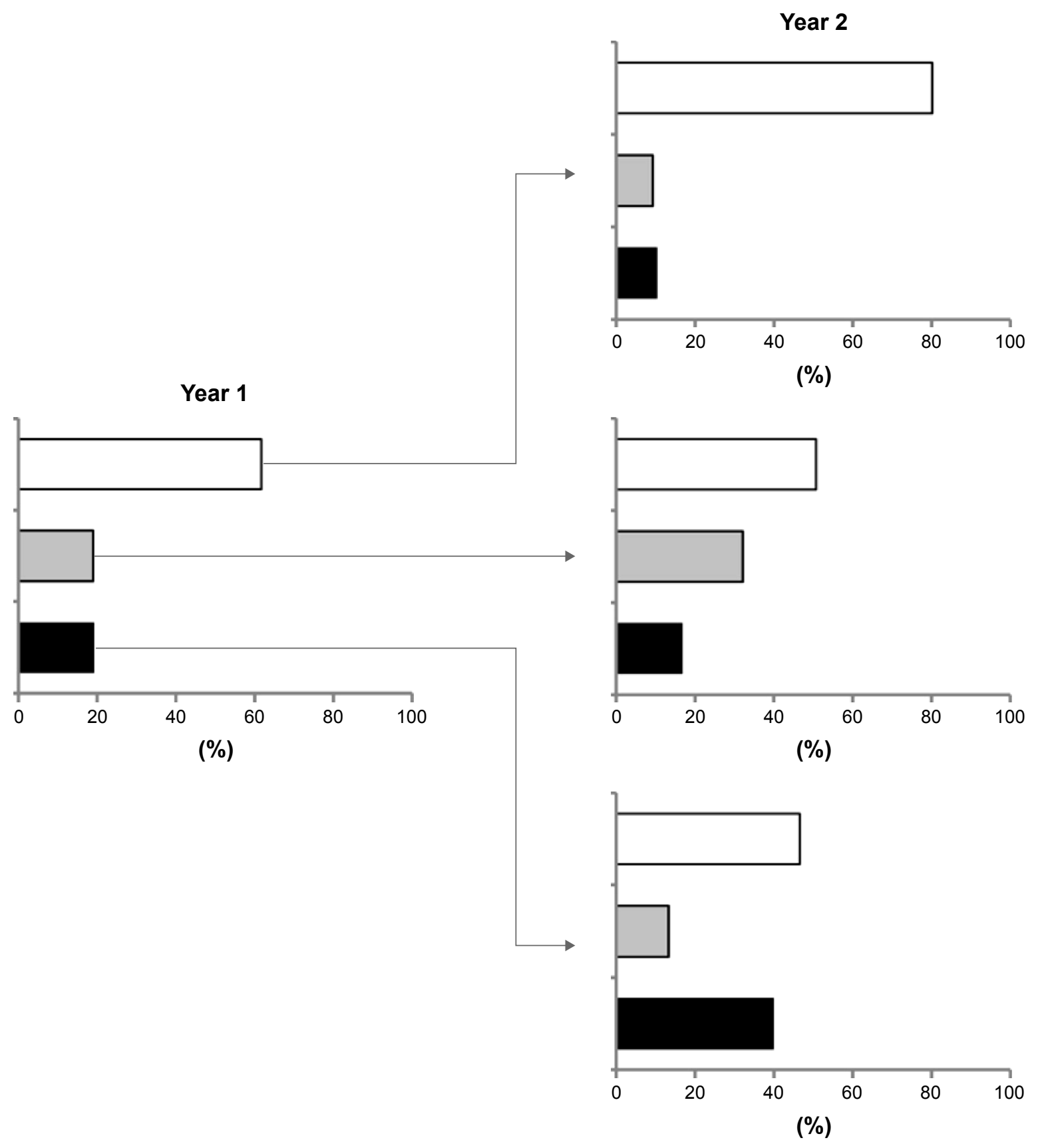

Figure I Frequency of exacerbation with different severities over 2 years.

Notes: Patients with no $(\square)$, mild $(\square)$, and moderate or severe $(\square)$ exacerbations. Bars on left: proportions of patients without, and with mild, and moderate or severe exacerbations during the first year of follow-up. Bars on right: respective incidence of exacerbations in these groups during the second year of follow-up.

comparable quantitative LAA\% data to determine annual changes in LAA $\%(n=179)$. The values for $\mathrm{LAA} \%$ and rates of change in LAA $\%$ did not significantly differ among the three groups during 2 years of follow-up $(P=0.0887$ and $P=0.3013$, respectively; Figure 3).

\section{Relationships between exacerbations and CAT and SGRQ scores during follow-up}

Not only did the moderate/severe exacerbator group significantly differ in total CAT scores during 2 years of follow-up compared with the exacerbation-free group $(P<0.001)$, but the mild exacerbator group also exhibited significant difference compared with the exacerbation-free group $(P=0.014)$. There was no difference between mild and moderate/severe exacerbator groups (Figure 4). The moderate/severe exacerbator group included seven patients who experienced more than two moderate or severe exacerbations during each year, and their CAT scores at baseline were 16.5 (interquartile range, 5.75-28.75). Among the eight items comprising CAT scores, a significant difference persisted in the respiratory symptom 
Table 2 Comparison of baseline characteristics among patients stratified according to severity of exacerbation

\begin{tabular}{|c|c|c|c|c|}
\hline & $\begin{array}{l}\text { Exacerbation } \\
\text { free }\end{array}$ & $\begin{array}{l}\text { Mild } \\
\text { exacerbator }\end{array}$ & $\begin{array}{l}\text { Moderate/severe } \\
\text { exacerbator }\end{array}$ & $P$-value \\
\hline Number (\%) & $154(49.5)$ & $67(2 \mid .5)$ & $90(29.0)$ & \\
\hline Sex, female (\%) & II (7.I) & $4(6.0)$ & $6(6.7)$ & 0.95 \\
\hline Age (years) & $72.5 \pm 8.3$ & $71.3 \pm 8.1$ & $74.0 \pm 7.6$ & 0.11 \\
\hline Smoking index (pack-years) & $53.2 \pm 27.7$ & $57.6 \pm 34.7$ & $61.2 \pm 27.7$ & 0.14 \\
\hline Current smokers (\%) & $21(13.9)$ & $8(11.9)$ & $9(10.5)$ & 0.73 \\
\hline BMI $\left(\mathrm{kg} / \mathrm{m}^{2}\right)$ & $23.0 \pm 3.2$ & $22.8 \pm 2.9$ & $22.0 \pm 3.0^{\mathrm{a}}$ & 0.033 \\
\hline$\% \mathrm{FEV}_{1}$ & $67.4 \pm 19.3$ & $65.4 \pm 21.9$ & $53.3 \pm 19 .\left.\right|^{a, b}$ & $<0.0001$ \\
\hline$\% \mathrm{DL}_{\mathrm{CO}} / V_{\mathrm{A}}(\%)(\mathrm{n}=235)$ & $65.4 \pm 20.8$ & $67.7 \pm 24.1$ & $55.6 \pm 21.2^{\mathrm{a}, \mathrm{b}}$ & 0.0043 \\
\hline LAA\% $(n=209)$ & $10.6(4.7-23.5)$ & $9.0(5.2-19.1)$ & $20.3(10.3-35.8)^{\mathrm{a}, \mathrm{b}}$ & 0.0006 \\
\hline WA\% $(n=206)$ & $54.1(47.9-59.1)$ & $52.2(46.8-57.0)$ & $50.4(43.9-57.2)$ & 0.2 \\
\hline LABA (\%) & 40.26 & 43.28 & $66.29^{a, b}$ & 0.0003 \\
\hline LAMA (\%) & 56.58 & 58.21 & 65.17 & $0.4 \mathrm{I}$ \\
\hline ICS (\%) & 26.62 & 32.84 & $47.19^{\mathrm{a}}$ & 0.0048 \\
\hline OCS (\%) & 1.32 & 0 & $5.75^{b}$ & 0.033 \\
\hline PPI (\%) & 12.5 & 16.67 & 21.84 & 0.17 \\
\hline Clarithromycin (\%) & 0.65 & 1.49 & $8.9^{a, b}$ & 0.0014 \\
\hline Carbocysteine (\%) & 8.44 & 5.97 & $26.67^{\mathrm{a}, \mathrm{b}}$ & $<0.0001$ \\
\hline CRP $(\mathrm{mg} / \mathrm{dL})$ & $0.32 \pm 0.98$ & $0.29 \pm 0.66$ & $0.43 \pm 0.9$ & 0.54 \\
\hline $\mathrm{SAA}(\mu \mathrm{g} / \mathrm{mL})$ & $17.0 \pm 69.7$ & $11.3 \pm 16.2$ & $23.7 \pm 65.2$ & 0.57 \\
\hline WBC $(\mu \mathrm{L})$ & $6,198.6 \pm 1,520.1$ & $6,065.0 \pm 2,084.8$ & $6,529.1 \pm 1,944.8$ & 0.22 \\
\hline Eo (\%) & $3.7 \pm 4.5$ & $3.3 \pm 3.6$ & $3.9 \pm 3.0$ & 0.61 \\
\hline
\end{tabular}

Notes: Data are shown as $n(\%)$ and mean $\pm S D$. ${ }^{a} P<0.05$ vs no exacerbation and ${ }^{b} P<0.05$ vs mild.


expiratory volume in I second; ICS, inhaled corticosteroids; LAA\%, ratio of low attenuation area; LABA, long-acting beta agonist; LAMA, long-acting muscarinic antagonist; OCS, oral corticosteroids; PPI, proton pump inhibitor; SAA, serum amyloid A; WA\%, ratio of airway wall area; WBC, white blood cell.

Table 3 Comparison of baseline comorbidities among patients stratified according to severity of exacerbation

\begin{tabular}{|c|c|c|c|c|c|}
\hline & Prevalence (\%) & $\begin{array}{l}\text { Exacerbation } \\
\text { free }\end{array}$ & $\begin{array}{l}\text { Mild } \\
\text { exacerbator }\end{array}$ & $\begin{array}{l}\text { Moderate/severe } \\
\text { exacerbator }\end{array}$ & $P$-value \\
\hline GERD (FSSG $\geq 8$ ) & $33.78(n=101)$ & $45(30.4 I)$ & $30(46.15)^{\mathrm{a}, \mathrm{b}}$ & $26(30.23)$ & 0.058 \\
\hline Anxiety (HADS-A $\geq I I)$ & $6.62(n=20)$ & $10(6.71)$ & $4(5.97)$ & $6(6.98)$ & 0.97 \\
\hline Depression (HADS-D $\geq \mathrm{II}$ ) & $8.61(n=26)$ & $9(6.04)$ & $7(10.45)$ & $10(11.63)$ & 0.28 \\
\hline Anemia & $22.76(n=71)$ & $27(17.53)$ & $17(25.37)$ & $27(29.67)^{\mathrm{a}}$ & 0.077 \\
\hline Osteoporosis & $14.1 \quad(n=32)$ & $14(12.07)$ & $5(9.26)$ & $13(22.81)^{c}$ & 0.082 \\
\hline Hypertension & $38.41(n=116)$ & $61(40.94)$ & $22(33.33)$ & $33(37.93)$ & 0.57 \\
\hline Diabetes mellitus & $14.57(n=44)$ & $23(15.44)$ & $6(9.09)$ & $15(17.24)$ & 0.34 \\
\hline Dyslipidemia & $|8.2|(n=55)$ & $31(20.81)$ & II (I6.67) & $13(14.94)$ & 0.5 \\
\hline Hyperuricemia & $8.94(n=27)$ & $13(8.72)$ & $8(12.12)$ & $6(6.9)$ & 0.53 \\
\hline Coronary artery disease & $12.58(n=38)$ & $21(14.09)$ & $6(9.09)$ & II (I2.64) & 0.72 \\
\hline Chronic heart disease & $6.62(n=20)$ & $10(6.71)$ & $6(9.09)$ & $4(4.6)$ & 0.54 \\
\hline Arrhythmia & $10.93(n=33)$ & $17(11.4 \mid)$ & $7(10.6 \mathrm{I})$ & $9(10.35)$ & 0.6 \\
\hline Cerebral infarction & $5.3(n=16)$ & $10(6.7 I)$ & $2(3.03)$ & $4(4.6)$ & 0.51 \\
\hline Peptic ulcer & $8.61(n=26)$ & II (7.38) & $5(7.58)$ & $10(11.49)$ & 0.52 \\
\hline Lung cancer & $5.3(n=16)$ & $6(4.03)$ & $4(6.06)$ & $6(6.9)$ & 0.61 \\
\hline Other cancer & $20.2(n=6 I)$ & $27(18.12)$ & $14(2 \mid .2 \mathrm{I})$ & $20(22.99)$ & 0.65 \\
\hline Chronic sinusitis & $12.75(n=39)$ & $19(12.58)$ & II (I6.42) & $9(10.23)$ & 0.52 \\
\hline Aortic aneurysm & $3.97(n=12)$ & $7(4.7)$ & $2(3.03)$ & $3(3.45)$ & 0.81 \\
\hline Chronic renal failure & $1.6 \mid(n=5)$ & I $(0.65)$ & $3(4.48)$ & I (I.II) & 0.11 \\
\hline Liver cirrhosis & $3.02(n=9)$ & $5(3.4)$ & I (I.54) & $3(3.49)$ & 0.73 \\
\hline Cataract & $46.54(n=101)$ & $46(40.35)$ & $20(4 I .67)$ & $35(63.64)^{a, c}$ & 0.013 \\
\hline Glaucoma & $7.83(n=17)$ & $6(5.31)$ & $4(8.33)$ & $7(12.5)$ & 0.26 \\
\hline Prostatic hypertrophy & $13.9 \mid(n=42)$ & $13(8.72)$ & II (I6.67) & $18(20.69)^{\mathrm{a}}$ & 0.029 \\
\hline
\end{tabular}

Notes: Data are shown as $\mathrm{n}(\%) .{ }^{\mathrm{a}} \mathrm{P}<0.05$ vs no exacerbation. ${ }^{\mathrm{b}} \mathrm{P}<0.05$ vs moderate or severe exacerbation. ${ }^{\mathrm{c} P}<0.05$ vs mild exacerbation.

Abbreviations: FSSG, frequency scale for the symptoms of GERD; GERD, gastroesophageal reflux disease; HADS, hospital anxiety and depression scale. 




Figure 2 Annual changes in $\mathrm{FEV}_{1}$ in three groups of patients over 2 years of follow-up. Notes: Patients in the exacerbation-free $(\bullet \bullet \boldsymbol{\Delta} \bullet \bullet)$, mild exacerbator $(-\mathrm{O}-)$, and moderate/severe exacerbator (- -$)$ groups. Moderate/severe exacerbator vs exacerbation free, $P<0.001$; mild exacerbator vs exacerbation free, $P=1.000$; and mild exacerbator vs moderate/severe exacerbator, $P=0.00 \mathrm{I}$.

Abbreviation: $\mathrm{FEV}_{1}$, forced expiratory volume in I second.

components of cough, sputum, and dyspnea and their activity $(P=0.0002, P=0.0006, P<0.0001$, and $P=0.0045$, respectively). We assessed the effect of mild exacerbation on CAT scores using multivariate logistic regression analysis that included risk factors that either reached significance or trended toward an association on univariate analysis. Severe airflow limitation $\left(\% \mathrm{FEV}_{1}<50 \%\right)$ and mild exacerbation independently advanced the likelihood of $\triangle \mathrm{CAT} \geq 2$ per year ( $P=0.042$ and $P=0.028$, respectively; Table 4$)$.

The 2-year follow-up also revealed a significant difference in all categories of SGRQ scores between moderate/ severe exacerbator groups and exacerbation-free groups (total, $P<0.001$, Figure 5; symptoms; $P<0.001$, Figure 6; activity, $P<0.001$, Figure 7; impact, $P<0.001$, Figure 8 ). However, the mild exacerbator group exhibited significant

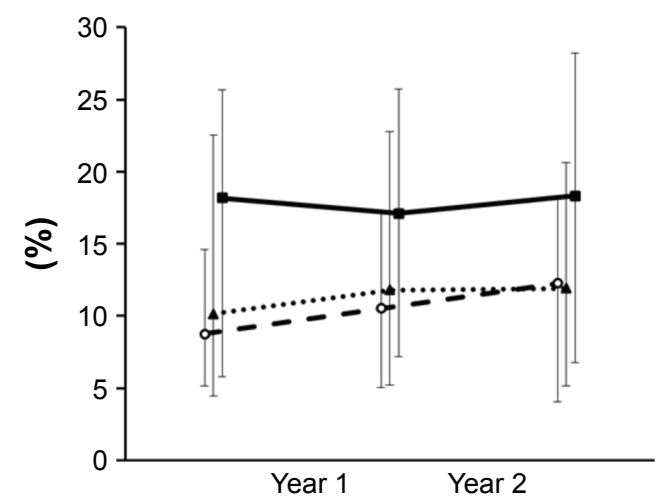

Figure 3 Annual changes in LAA\% in three groups of patients over 2 years of follow-up.

Notes: Patients in the exacerbation-free $(\bullet \bullet \mathbf{\Delta} \bullet \bullet)$, mild exacerbator $(-\mathrm{O}-)$, and moderate/severe exacerbator (-口-) groups. Moderate/severe exacerbator vs exacerbation free, $P=0.228$; mild exacerbator vs exacerbation free, $P=1.000$; and mild exacerbator vs moderate/severe exacerbator, $P=0.100$.

Abbreviation: LAA\%, ratio of low attenuation area.

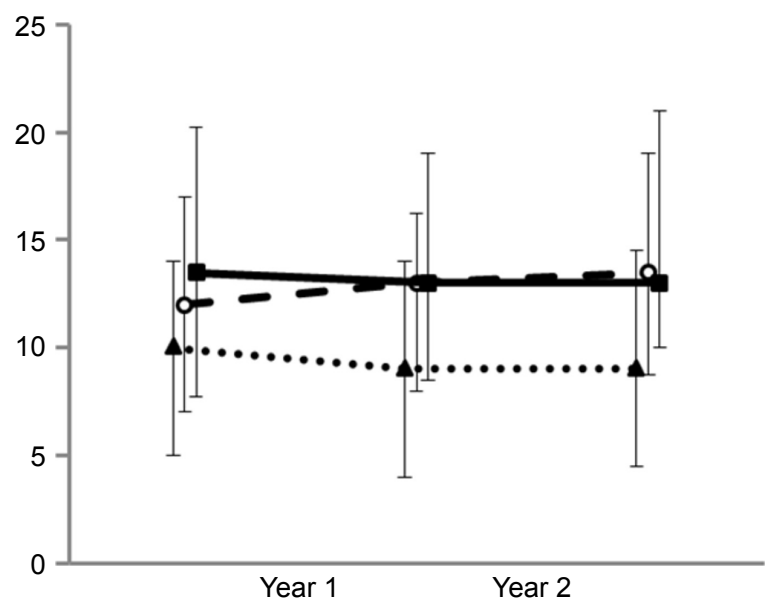

Figure 4 Annual changes in CAT scores in three groups of patients over 2 years of follow-up.

Notes: Patients in the exacerbation-free $(\bullet \bullet \boldsymbol{A} \bullet)$, mild exacerbator $(-\mathrm{O}-)$, and moderate/severe exacerbator (-口-) groups. Moderate/severe exacerbator vs exacerbation free, $P<0.001$; mild exacerbator vs exacerbation free, $P=0.014$; and mild exacerbator vs moderate/severe exacerbator, $P=0.493$.

Abbreviation: CAT, COPD assessment test.

difference compared with the exacerbation-free group only in total score and symptoms category of SGRQ (total, $P=0.041$, Figure 5; symptoms; $P=0.002$, Figure 6; activity, $P=0.226$, Figure 7; impact, $P=0.064$, Figure 8 ).

\section{Discussion}

Previous studies have shown that patients with moderate or severe exacerbations have a rapid decline in lung function ${ }^{32,33}$ and emphysema progression, ${ }^{16}$ an inferior health-related QOL, ${ }^{11}$ and decreased exercise performance. ${ }^{34}$ However, the influence of mild exacerbation on QOL, lung function, and emphysema has remained unclear. This study shows that steady-state CAT scores and the symptom component of SGRQ remained worse in the mild exacerbator group than in the exacerbation-free group during 2 years of follow-up, although the severity of $\mathrm{FEV}_{1}$ did not significantly differ. However, mild exacerbations

Table 4 Predictors of CAT (minimal clinical important difference; $\Delta$ CAT $\geq 2$ per year) increase determined by multivariate logistic regression analysis

\begin{tabular}{lll}
\hline & OR (95\% CI) & $P$-value \\
\hline $\begin{array}{l}\text { Airflow limitation } \\
\text { \%FEV },<50 \% \text { vs } \geq 50 \%\end{array}$ & $2.42(1.03-5.60)$ & 0.042 \\
$\begin{array}{l}\text { Acute exacerbation } \\
\quad \text { Mild exacerbation vs exacerbation free }\end{array}$ & $2.29(1.09-4.80)$ & 0.028 \\
$\begin{array}{l}\text { Comorbidity } \\
\quad \text { Depression (HADS-D } \geq \mathrm{II})\end{array}$ & $1.97(0.55-6.46)$ & 0.282 \\
$\quad$ Osteoporosis & $1.92(0.60-5.68)$ & 0.260 \\
\hline
\end{tabular}

Abbreviations: $\mathrm{Cl}$, confidence interval; CAT, COPD assessment test; \% FEV , ratio of predicted forced expiratory volume in I second; HADS, hospital anxiety and depression scale; OR, odds ratio. 




Figure 5 Annual changes in SGRQ total scores over 2 years of follow-up. Notes: Patients in the exacerbation-free $(\bullet \bullet \bullet \bullet)$, mild exacerbator $\left(-\mathrm{O}_{-}\right)$, and moderate/severe exacerbator (-口-) groups. Moderate/severe exacerbator vs exacerbation free, $P<0.00 \mathrm{I}$; mild exacerbator vs exacerbation free, $P=0.04 \mathrm{I}$; and mild exacerbator vs moderate/severe exacerbator, $P=0.013$.

Abbreviation: SGRQ, St George's Respiratory Questionnaire.

did not change the levels of activity or impact scores of SGRQ at steady state. The CAT and other SGRQ scores also remained worse in the moderate/severe exacerbator compared with the exacerbation-free group during 2 years of follow-up, but they were concomitant with a lower $\mathrm{FEV}_{1}$.

The unique point of this study was the focus on mild exacerbation. To ascertain, "mild" exacerbation is limited because perception of the actual symptoms is subjective. Many studies have tried to establish standardized methods, but some issues have arisen. ${ }^{35,36}$ Independent investigators in this study selected most of the patients with mild COPD exacerbation from detailed retrospective reviews of individual clinical records, in which patients reported issues such as having had a common cold since the last consultation

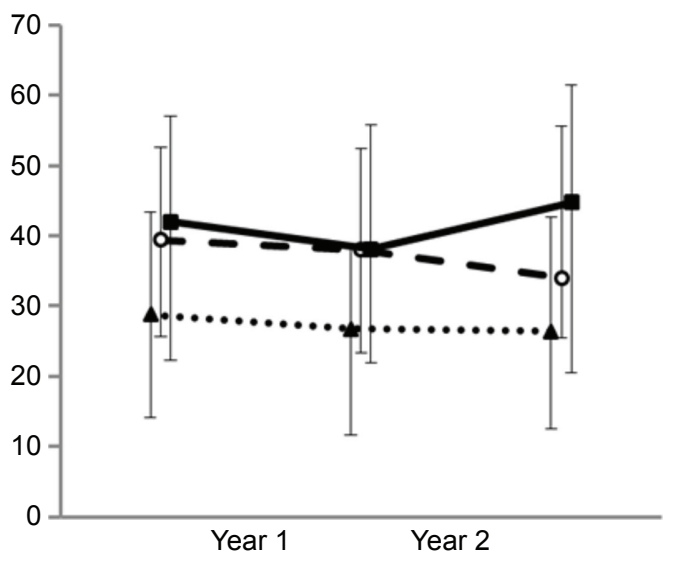

Figure 6 Annual changes in SGRQ symptoms category over 2 years of follow-up. Notes: Patients in the exacerbation-free $(\bullet \boldsymbol{\Delta} \bullet \bullet)$, mild exacerbator $\left(-\mathrm{O}_{-}\right)$, and moderate/severe exacerbator (-口-) groups. Moderate/severe exacerbator vs exacerbation free, $P<0.00 \mathrm{I}$; mild exacerbator vs exacerbation free, $P=0.002$; and mild exacerbator vs moderate/severe exacerbator, $P=1.000$. Abbreviation: SGRQ, St George's Respiratory Questionnaire.

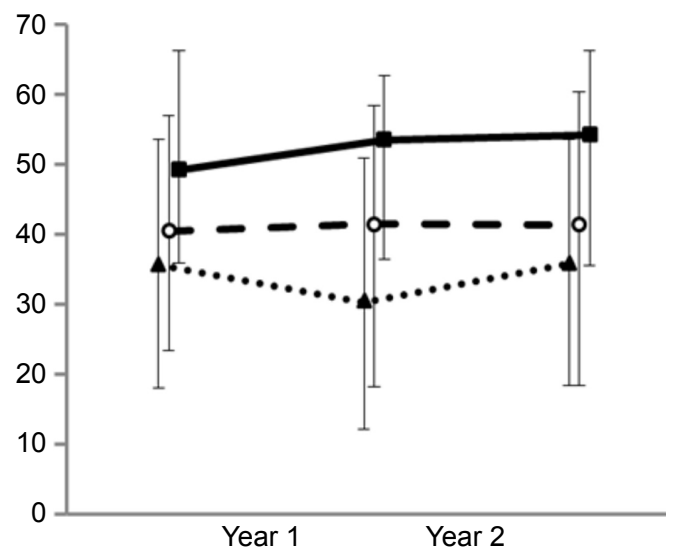

Figure 7 Annual changes in SGRQ activity category over 2 years of follow-up. Notes: Patients in the exacerbation-free $(\bullet \bullet \bullet \bullet)$, mild exacerbator $(-\mathrm{O}-)$, and moderate/severe exacerbator (- -$)$ groups. Moderate/severe exacerbator vs exacerbation free, $P<0.00$ I; mild exacerbator vs exacerbation free, $P=0.226$; and mild exacerbator vs moderate/severe exacerbator, $P=0.004$.

Abbreviation: SGRQ, St George's Respiratory Questionnaire.

with a respiratory physician. The physicians then assumed that the health status of the patient had been restored to normal without intervention with antibiotics and/or steroid. Sometimes, COPD exacerbation was objectively judged during an unscheduled primary care assessment or when a patient walked into an emergency center. Reliability depends on self-reported previous illness that patients need to recall over various periods. The investigators were aware of the limitation that the frequency of mild exacerbations might be underestimated because patients might forget episodes if they were very mild or very frequent or when they recognized that reporting was not needed. On the other hand, the risk of overestimating exacerbation severity must be minimal because patients report it after understanding the



Figure 8 Annual changes in SGRQ impact category over 2 years of follow-up. Notes: Patients in the exacerbation-free $(\bullet \bullet \bullet \bullet \bullet)$, mild exacerbator $(-\mathrm{O}-)$, and moderate/severe exacerbator (-[-) groups. Moderate/severe exacerbator vs exacerbation free, $P<0.00 \mathrm{I}$; mild exacerbator vs exacerbation free, $P=0.064$; and mild exacerbator vs moderate/severe exacerbator, $P=0.008$. Abbreviation: SGRQ, St George's Respiratory Questionnaire. 
consequences of recovery from such episodes compared with the patient diary approach. ${ }^{14,22}$

One of the major strengths of this study is the comprehensive assessment of comorbid factors in the K-CCR cohort study, which has been characterized in detail. Generally, it was reported that comorbidities of conditions, such as cardiac disease, ${ }^{37,38}$ GERD, ${ }^{39,40}$ and depression ${ }^{41}$ are associated with moderate or severe exacerbations. However, the frequency of these comorbidities did not significantly differ between moderate/severe exacerbator and exacerbationfree groups in the present study, which could be explained as follows. Japanese patients with COPD have different characteristics, such as more advanced age, lower BMI, emphysema-dominant type, ${ }^{15,42}$ and a different profile of comorbidities, compared with non-Japanese, as well as a lower prevalence of cardiovascular disease and metabolic syndrome and a higher frequency of osteoporosis and malnutrition. ${ }^{18,43}$ This study finds that symptoms of GERD are associated with mild exacerbations but not with moderate or severe exacerbations. Thus, GERD might cause mild exacerbations or comorbid GERD could worsen CAT and SGRQ scores. Whether or not treatment for GERD contributes to improve these scores in patients with mild exacerbations or decrease the frequency of mild exacerbations should be worth investigating. Interactions between host factors, bacteria, viruses, and air pollution are thought to exacerbate COPD. ${ }^{44}$ Human rhinovirus prevalence and load increased at COPD exacerbation and resolved during recovery. ${ }^{45}$ The etiology might be associated with differences in exacerbation severity.

Our cohort study showed that the current frequency of moderate or severe exacerbations of COPD is as low as that found in previous studies of Japanese patients with $\mathrm{COPD}^{15-17}$ and lower than that found in other countries ${ }^{7}$ and in some recent clinical trials. ${ }^{46,47}$ This discrepancy could be explained as follows. This study includes patients with mild airflow limitation (GOLD 1, 22.2\%), unlike previous clinical studies that did not recruit such patients. Our patients were mostly past smokers $(87.5 \%)$ and were regularly treated with bronchodilators $(72.3 \%)$. Although the reasons for the difference in exacerbation frequency remain to be defined, the difference in the low rate of exacerbation might not be unique to Japan, and they might have important implications for clinical trials of exacerbation.

This study is limited by the short observational period of only 2 years, and the fact that QOL scores, lung function, and chest CT images were only monitored annually. A longer follow-up with more frequent measures is required to develop a more thorough understanding of the long-term impact of mild exacerbation on the progression of clinical parameters. Large clinical trials of patients with COPD have shown that current treatments have significantly reduced moderate or severe exacerbations ${ }^{46,47}$ and early intervention also improves outcomes of exacerbations. ${ }^{13,48}$ However, the effectiveness of such treatments on mild exacerbations remains unknown.

\section{Conclusion}

Even mild exacerbations adversely impacted the healthrelated QOL of patients with COPD. Appropriate intervention for mild exacerbations, as well as moderate or severe ones, would be important for improving outcomes for patients with COPD.

\section{Acknowledgments}

The authors acknowledge Tsuyoshi Sakamoto from AZE Ltd. and Masahiro Jinzaki from the Department of Diagnostic Radiology, Keio University School of Medicine, for helping to analyze chest CT imaging findings and to calibrate the CT instruments and Chiyomi Uemura for helping in collecting the data. The authors acknowledge all the members of the K-CCR group who participated in this study, including Saiseikai Utsunomiya Hospital, Eiju General Hospital, Tokyo Saiseikai Central Hospital, Sano Public Welfare General Hospital, Nihon Kokan Hospital, Saitama Social Insurance Hospital, Kawasaki City Ida Hospital, Saitama City Hospital, Tokyo Medical Center, Tokyo Dental College Ichikawa General Hospital, Tokyo Electric Power Company Hospital, and the International Medical Welfare College Shioya Hospital.

\section{Author contributions}

Minako Sato and Shotaro Chubachi contributed to the study design, analyzed the data, and wrote the article. Mamoru Sasaki, Mizuha Haraguchi, Naofumi Kameyama, Akihiro Tsutsumi, and Saeko Takahashi contributed to patient enrollment and acquisition of their clinical information. Hidetoshi Nakamura and Koichiro Asano were involved in the study design. Tomoko Betsuyaku planned and supervised the study and wrote the article. All authors contributed toward data analysis, drafting and critically revising the paper and agree to be accountable for all aspects of the work.

\section{Disclosure}

Tomoko Betsuyaku received honoraria/paid expert testimony, and her university received research grants from 
GlaxoSmithKline. The authors report no other conflicts of interest in this work.

\section{References}

1. Vestbo J, Hurd SS, Agustí AG, et al. Global strategy for the diagnosis, management, and prevention of chronic obstructive pulmonary disease: GOLD executive summary. Am J Respir Crit Care Med. 2013;187(4):347-365.

2. Soler-Cataluña JJ, Martínez-García MA, Román Sánchez P, Salcedo E, Navarro M, Ochando R. Severe acute exacerbations and mortality in patients with chronic obstructive pulmonary disease. Thorax. 2005; 60(11):925-931.

3. Almagro P, Soriano JB, Heredia JL, et al; Working Group on COPD; Spanish Society of Internal Medicine. Short- and medium-term prognosis in patients hospitalized for COPD exacerbation: the CODEX index. Chest. 2014;145(5):972-980.

4. de Miguel-Díez J, Jiménez-García R, Carrasco-Garrido P, et al. Trends in hospital admissions for acute exacerbation of COPD in Spain from 2006 to 2010. Respir Med. 2013;107(5):717-723.

5. Blasi F, Cesana G, Mantovani LG, et al. The clinical and economic impact of exacerbations of chronic obstructive pulmonary disease a cohort of hospitalized patients. PLoS One. 2014;9(6):e101228.

6. Wedzicha JA, Brill SE, Allinson JP, Donaldson GC. Mechanisms and impact of the frequent exacerbator phenotype in chronic obstructive pulmonary disease. BMC Med. 2013;11:181.

7. Hurst JR, Vestbo J, Anzueto A, et al; Evaluation of COPD Longitudinally to Identify Predictive Surrogate Endpoints (ECLIPSE) Investigators. Susceptibility to exacerbation in chronic obstructive pulmonary disease. N Engl J Med. 2010;363(12):1128-1138.

8. Wedzicha JA, Decramer M, Ficker JH, et al. Analysis of chronic obstructive pulmonary disease exacerbations with the dual bronchodilator QVA149 compared with glycopyrronium and tiotropium (SPARK): a randomised, double-blind, parallel-group study. Lancet Respir Med. 2013;1(3):199-209.

9. Tomioka R, Kawayama T, Hoshino T, et al. "Frequent exacerbator" is a phenotype of poor prognosis in Japanese patients with chronic obstructive pulmonary disease. Int J Chron Obstruct Pulmon Dis. 2016;11:207-216.

10. Anthonisen NR, Manfreda J, Warren CP, Hershfield ES, Harding GK, Nelson NA. Antibiotic therapy in exacerbations of chronic obstructive pulmonary disease. Ann Intern Med. 1987;106(2):196-204.

11. Miravitlles M, Ferrer M, Pont A, et al; IMPAC Study Group. Effect of exacerbations on quality of life in patients with chronic obstructive pulmonary disease: a 2 year follow up study. Thorax. 2004;59(5):387-395.

12. Seemungal TA, Donaldson GC, Bhowmik A, Jeffries DJ, Wedzicha JA Time course and recovery of exacerbations in patients with chronic obstructive pulmonary disease. Am J Respir Crit Care Med. 2000;161(5): 1608-1613.

13. Wilkinson TM, Donaldson GC, Hurst JR, Seemungal TA, Wedzicha JA. Early therapy improves outcomes of exacerbations of chronic obstructive pulmonary disease. Am J Respir Crit Care Med. 2004;169(12): 1298-1303.

14. Langsetmo L, Platt RW, Ernst P, Bourbeau J. Underreporting exacerbation of chronic obstructive pulmonary disease in a longitudinal cohort. Am J Respir Crit Care Med. 2008;177(4):396-401.

15. Fukuchi Y, Fernandez L, Kuo HP, et al. Efficacy of tiotropium in COPD patients from Asia: a subgroup analysis from the UPLIFT trial. Respirology. 2011;16(5):825-835.

16. Tanabe N, Muro S, Hirai T, et al. Impact of exacerbations on emphysema progression in chronic obstructive pulmonary disease. Am J Respir Crit Care Med. 2011;183(12):1653-1659.

17. Suzuki M, Makita H, Ito YM, et al; Hokkaido COPD Cohort Study Investigators. Clinical features and determinants of COPD exacerbation in the Hokkaido COPD cohort study. Eur Respir J. 2014;43(5):1289-1297.

18. Miyazaki M, Nakamura H, Chubachi S, et al; Keio COPD Comorbidity Research (K-CCR) Group. Analysis of comorbid factors that increase the COPD assessment test scores. Respir Res. 2014;15:13.
19. Chubachi S, Nakamura H, Sasaki M, et al; Keio COPD Comorbidity Research (K-CCR) Group. Polymorphism of LRP5 gene and emphysema severity are associated with osteoporosis in Japanese patients with or at risk for COPD. Respirology. 2015;20(2):286-295.

20. Miyazaki M, Nakamura H, Takahashi S, et al; Keio COPD Comorbidity Research (K-CCR) Group. The reasons for triple therapy in stable COPD patients in Japanese clinical practice. Int J Chron Obstruct Pulmon Dis. 2015;10:1053-1059.

21. Nagai K, Makita H, Suzuki M, et al; Hokkaido COPD Cohort Study Investigators. Differential changes in quality of life components over 5 years in chronic obstructive pulmonary disease patients. Int J Chron Obstruct Pulmon Dis. 2015;10:745-757.

22. Seemungal TA, Donaldson GC, Paul EA, Bestall JC, Jeffries DJ, Wedzicha JA. Effect of exacerbation on quality of life in patients with chronic obstructive pulmonary disease. Am J Respir Crit Care Med. 1998;157(5 Pt 1):1418-1422.

23. Jones PW, Quirk FH, Baveystock CM, Littlejohns P. A self-complete measure of health status for chronic airflow limitation. The St. George's Respiratory Questionnaire. Am Rev Respir Dis. 1992; 145(6):1321-1327.

24. Hajiro T, Nishimura K, Tsukino M, Ikeda A, Koyama H, Izumi T. Comparison of discriminative properties among disease-specific questionnaires for measuring health-related quality of life in patients with chronic obstructive pulmonary disease. Am J Respir Crit Care Med. 1998;157(3 Pt 1):785-790.

25. Hajiro T, Nishimura K, Tsukino M, Ikeda A, Koyama H, Izumi T. Analysis of clinical methods used to evaluate dyspnea in patients with chronic obstructive pulmonary disease. Am J Respir Crit Care Med. 1998;158(4):1185-1189.

26. Jones PW, Harding G, Berry P, Wiklund I, Chen WH, Kline Leidy N. Development and first validation of the COPD assessment test. Eur Respir J. 2009;34(3):648-654.

27. Kwon N, Amin M, Hui DS, et al. Validity of the COPD assessment test translated into local languages for Asian patients. Chest. 2013;143(3): 703-710.

28. Camiciottoli G, Bigazzi F, Paoletti M, Cestelli L, Lavorini F, Pistolesi M. Pulmonary function and sputum characteristics predict computed tomography phenotype and severity of COPD. Eur Respir J. 2013; 42(3):626-635.

29. Tanabe N, Muro S, Tanaka S, et al. Emphysema distribution and annual changes in pulmonary function in male patients with chronic obstructive pulmonary disease. Respir Res. 2012;13:31.

30. Kon SS, Canavan JL, Jones SE, et al. Minimum clinically important difference for the COPD Assessment Test: a prospective analysis. Lancet Respir Med. 2014;2(3):195-203.

31. Raudenbush SW, Bryk AS. Hierarchical Linear Models. Newbury Park, NJ: Sage; 2002.

32. Halpin DM, Decramer M, Celli B, Kesten S, Liu D, Tashkin DP. Exacerbation frequency and course of COPD. Int J Chron Obstruct Pulmon Dis. 2012;7:653-661.

33. Donaldson GC, Seemungal TA, Patel IS, Lloyd-Owen SJ, Wilkinson TM, Wedzicha JA. Longitudinal changes in the nature, severity and frequency of COPD exacerbations. Eur Respir J. 2003;22(6):931-936.

34. Pitta F, Troosters T, Probst VS, Spruit MA, Decramer M, Gosselink R. Physical activity and hospitalization for exacerbation of COPD. Chest. 2006;129(3):536-544.

35. Mackay AJ, Donaldson GC, Patel AR, Singh R, Kowlessar B, Wedzicha JA. Detection and severity grading of COPD exacerbations using the exacerbations of chronic pulmonary disease tool (EXACT). Eur Respir $J$. 2014;43(3):735-744.

36. Trappenburg JC, Touwen I, de Weert-van Oene GH, et al. Detecting exacerbations using the clinical COPD questionnaire. Health Qual Life Outcomes. 2010;8:102.

37. McGarvey L, Lee AJ, Roberts J, Gruffydd-Jones K, McKnight E, Haughney J. Characterisation of the frequent exacerbator phenotype in COPD patients in a large UK primary care population. Respir Med. 2015;109(2):228-237. 
38. Brekke PH, Omland T, Smith P, Søyseth V. Underdiagnosis of myocardial infarction in COPD - cardiac infarction injury score (CIIS) in patients hospitalised for COPD exacerbation. Respir Med. 2008;102(9): 1243-1247.

39. Terada K, Muro S, Sato S, et al. Impact of gastro-oesophageal reflux disease symptoms on COPD exacerbation. Thorax. 2008;63(11): 951-955.

40. Martinez CH, Okajima Y, Murray S, et al; COPD Gene Investigators. Impact of self-reported gastroesophageal reflux disease in subjects from COPD Gene cohort. Respir Res. 2014;15:62.

41. Xu W, Collet JP, Shapiro S, et al. Independent effect of depression and anxiety on chronic obstructive pulmonary disease exacerbations and hospitalizations. Am J Respir Crit Care Med. 2008;178(9):913-920.

42. Tatsumi K, Kasahara Y, Kurosu K, et al; Respiratory Failure Research Group in Japan. Clinical phenotypes of COPD: results of a Japanese epidemiological survey. Respirology. 2004;9(3):331-336.

43. Takahashi S, Betsuyaku T. The chronic obstructive pulmonary disease comorbidity spectrum in Japan differs from that in western countries. Respir Investig. 2015;53(6):259-270.
44. Dai MY, Qiao JP, Xu YH, Fei GH. Respiratory infectious phenotypes in acute exacerbation of COPD: an aid to length of stay and COPD Assessment Test. Int J Chron Obstruct Pulmon Dis. 2015; 10:2257-2263.

45. George SN, Garcha DS, Wedzicha JA, et al. Human rhinovirus infection during naturally occurring COPD exacerbations. Eur Respir J. 2014; 44(1):87-96.

46. Calverley PM, Anderson JA, Celli B, et al; TORCH Investigators. Salmeterol and fluticasone propionate and survival in chronic obstructive pulmonary disease. $N$ Engl J Med. 2007;356(8):775-789.

47. Tashkin DP, Celli B, Senn S, et al; UPLIFT Study Investigators. A 4-year trial of tiotropium in chronic obstructive pulmonary disease. N Engl J Med. 2008;359:1543-1554.

48. Gadoury MA, Schwartzman K, Rouleau M, et al; Chronic Obstructive Pulmonary Disease Axis of the Respiratory Health Network, Fonds de la recherche en santé du Québec (FRSQ). Self-management reduces both short- and long-term hospitalisation in COPD. Eur Respir J. 2005; 26(5):853-857.

\section{Publish your work in this journal}

The International Journal of COPD is an international, peer-reviewed journal of therapeutics and pharmacology focusing on concise rapid reporting of clinical studies and reviews in COPD. Special focus is given to the pathophysiological processes underlying the disease, intervention programs, patient focused education, and self management protocols.

\section{Dovepress}

This journal is indexed on PubMed Central, MedLine and CAS. The manuscript management system is completely online and includes a very quick and fair peer-review system, which is all easy to use. Visit http://www.dovepress.com/testimonials.php to read real quotes from published authors. 